\title{
Fuzzy Controlled ZVS Asymmetrical PWM Full-bridge DC-DC Converter for Constant load High Power Applications
}

\author{
Marikkannan. $A^{\dagger}$ and Manikandan. B.V*
}

\begin{abstract}
This paper proposes a fuzzy logic controlled new topology of high voltage gain zero voltage switching (ZVS) asymmetrical PWM full-bridge DC-DC boost converter for constant load and high power applications.The APWM full-bridge stage provides high voltage gain and soft-switching characteristics increase the efficiency and reduce the switching losses. Fuzzy logic controller (FLC) improves the performance and dynamic characteristics of the proposed converter. A comparison with a classical proportional-integral (PI) controller demonstrates the high performances of the proposed technique in terms of effective output voltage regulation under different operating conditions. Simulation is done by integrating two different simulation platforms PSIM $^{\circledR}$ and Matlab ${ }^{\circledR} /$ Simulink $^{\circledR}$ by using SimCoupler tool of PSIM ${ }^{\circledR}$. Experimental results using $120 \mathrm{~W}$ load have been provided to validate the results.
\end{abstract}

Keywords: Asymmetrical PWM, Full-bridge DC-DC boost converter, Fuzzy logic controller, High voltage gain, Proportional Integral controller

\section{Introduction}

A variety of different topology of high step-up dc-dc converters have been researched due to their growing demands in applications such as electric vehicles, uninterruptible power supplies, micro-inverter, fuel cells, and photovoltaic systems [1, 3, 5, 7-12, 14, 19]. Even high voltage gain is the main requirement of dc-dc boost converter and there are several other necessities such as low input current ripple, high power density, low transformer turn ratio, and high efficiency. Input current ripple is important critical factor in between them. It is because large input current ripple may shorten the lifetimes as well as decreasing performances of the input sources such as low voltage batteries and fuel cells $[12,15]$. Number of four switches and one capacitor combined converter module is connected in series to construct transformerless step up converter for medium voltage and megawatts power applications [2]. Converter switches are controlled with soft switching.

A non-isolated single switch high voltage gain DC-DC boost converter is designed with combination of voltagelift and multiplier circuits [4].Converter consists of n-stages of diode, capacitor and inductor unit is used to get high voltage gain at low duty ratio. Controllability of converter is increased and makes possible to operate in three conduction regions. By integrating traditional boost converter with self-lift SEPIC converter, a new non-

$\dagger$ Corresponding Author: Dept. of Electrical and Electronic Engineering, Sree Sowdambika College of Engineering, Tamil Nadu, India. (mari.innofx@gmail.com)

* Dept. of Electrical and Electronic Engineering, MEPCO Schlenk Engineering College, Tamil Nadu, India. (bvmani73@yahoo.com)

Received: July 12, 2016; Accepted: March 12, 2017 isolated high voltage ratio, low voltage stress and low conduction loss DC-DC converter is developed [5]. It gives high voltage gain without extreme high duty ratio. For micro-inverter applications a new converter topology is formed by integrating quadratic boost converter stepup capability and tapped inductor based converter [6]. It gives high voltage ratio at low duty ratio. A novel single switch ZVS and ZCS DC-DC boost converter [7] is constructed for photovoltaic based battery charging applications. It has improved efficiency due to low switching losses. In [9], half-bridge fly-back converter is soft-switching controlled by using asymmetrical PWM control for solar power conversion applications. Simple topology and operation makes this converter for power applications. Due to half-bridge topology, this converter does not give good efficiency at high power conversion.

Different optimal topologies of boost converter are designed to track maximum power from solar cell [10]. These converter topologies meet solar cell irradiance and temperature variations. Eliminated switching loss and low conduction loss are obtained byasymmetrical switching of full-bridge converter [11]. In this converter soft-switching is achieved through asymmetrical switching. Interleaved soft-switching DC-DC boost converter for photovoltaic power conversion is presented [12]. Efficiency of converter is increased due to soft-switching.

In [13] discontinuous conduction mode (DCM) frequency control algorithm is proposed for multi-phase interleaved boost converter. Input current ripple is reduced by given control algorithm. Stability of boost converter is analysed with traditional peak current mode, voltage mode and average current mode control for maximum power tracking from solar panel [14]. Takagi-Sugeno fuzzy model-based 
robust fuzzy logic controller and fuzzy load conductance observer for DC-DC boost converter is designed [16]. State trajectory approximation based new control scheme for regulate the output voltage of DC-DC converter is presented [17]. By using this control algorithm converter is maintained its stable limit cycle to ensure voltage regulation. Combination of $\mathrm{K}$-factor, gravitational search algorithm and particle swarm optimisation approach [18] is used with type-II and type-III controller for DC-DC boost converter to give good performance. In [19] two phase interleaved DC-DC boost converter is controlled by single chip DSP to improve reliability and flexibility for fuel cell applications.

In major applications, DC-DC converters are required to deliver regulated output voltage with minimal steady-state output error, fast dynamical response, low overshoot and low sensitivity to the noise, and also to the input voltage deviations, to the load transients and to the variation of the characteristics of the passive components (inductors, capacitors, switches) due to their aging. All these requirements have to be satisfied both through the correct design of the circuit parameters and components and, mostly, by the implementation of appropriate control methodologies.

This paper provides a fuzzy logic controller for ZVS APWM full-bridge dc-dc converter. It does not require mathematical model of converter. Comparison with a classical proportional-integral (PI) controller demonstrates the improved performances of the proposed solution in terms of fast and effective output voltage regulation under different severe operating conditions.

\section{Fuzzy Logic and Fuzzy Sets}

The block diagram of the fuzzy logic control scheme of ZVS Asymmetrical full-bridge DC-DC converter is used is shown in Fig. 1. The fuzzy controller is divided into five components: fuzzifier, data base, rule base, decision maker, and defuzzifier. Before going through the details of fuzzy controller design, some basic definitions and mathematical operations of fuzzy sets are described as follows.

\subsection{Definition of a fuzzy set}

Definition 1 (Fuzzy set). Let $X$ be a collection of objects ( $X$ is the universal set); then a fuzzy set $\mathrm{A}$ in $\mathrm{X}$ is defined to be a set of ordered pairs:

$$
\tilde{\mathrm{A}}=\left\{\left(\mathrm{x}, \mu_{\mathrm{A}}(\mathrm{x})\right) \mid \mathrm{x} \in \mathrm{X}\right\}
$$

where $\mu_{A}(x)$ is called the membership function of $x$ in $\tilde{A}$.

Note that the membership function $\mu_{A}(x)$ denotes the degree that $x$ belongs to $\widetilde{A}$ and is normally limited to values between 0 and 1 .

A high value of $\mu_{\widetilde{A}}(x)$ implies that it is very likely for $x$

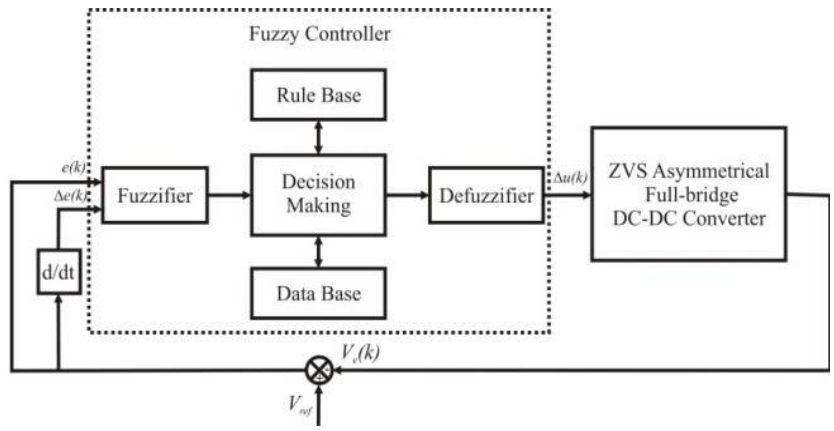

Fig. 1. Block diagram of fuzzy control scheme for proposed converter

to be in $\tilde{A}$.

Elements with a zero degree of membership are normally not listed. If we limit the value of the membership function to either 0 or 1 , then $\widetilde{A}$ becomes a crisp (nonfuzzy) set.

\subsection{Fuzzy set operation}

Definition 2 (The AND operator (the intersection of two fuzzy sets)). Let $\widetilde{A}$ and $\widetilde{B}$ be two fuzzy sets with membership functions $\mu_{\tilde{A}}(x)$ and $\mu_{\widetilde{B}}(x)$, respectively. The membership function of the intersection (AND), $\widetilde{C}=\widetilde{A} \cap \widetilde{B}$, is defined as

$$
\mu_{\tilde{C}}(x)=\min \left(\mu_{\tilde{A}}(x), \mu_{\tilde{B}}(x)\right), \quad x \hat{I} X
$$

Definition 3 (The OR operator (the union of two fuzzy sets)). Let $\widetilde{A}$ and $\widetilde{B}$ be two fuzzy sets with membership functions $\mu_{\widetilde{A}}(x)$ and $\mu_{\widetilde{B}}(x)$, The membership function of the union (OR), $\widetilde{D}=\widetilde{A} \cup \widetilde{B}$, is defined as

$$
\mu_{\tilde{D}}(x)=\max \left(\mu_{\tilde{A}}(x), \mu_{\tilde{B}}(x)\right), \quad x \in X
$$

Definition 4 (The NOT operator (the complement of a fuzzy set)). Let $\tilde{A}$ be a fuzzy set with membership function $\mu_{\tilde{A}}(x)$. The membership function of the complement of $\widetilde{A}, \tilde{c} \widetilde{A}$, is defined as

$$
\mu_{c \tilde{A}}(x)=1-\mu_{\tilde{A}}(x), \quad x \in \tilde{A}
$$

Definition 5 (Fuzzy relation). Let $\widetilde{A}$ and $\widetilde{B}$ be two fuzzy sets with membership functions $\mu_{\tilde{A}}(x)$ and $\mu_{\tilde{B}}(x)$, respectively. A fuzzy relation $\mathrm{R}$ from $\widetilde{A}$ to $\widetilde{B}$ can be visualized as a fuzzy graph and can be characterized by the membership function $\mu_{\tilde{R}}(x, y)$, which satisfies the composition rule as follows:

$$
\mu_{\tilde{B}}(y)=\max _{x}\left(\min \left(\mu_{\tilde{R}}(x, y), \mu_{\tilde{A}}(x)\right)\right)
$$

\subsection{Derivation of fuzzy logic controller for full-bridge converter}

Proposed ZVS asymmetrical PWM full-bridge DC-DC 
converter with fuzzy logic controller shown in Fig. 1 is demonstrated in this paper. The fuzzy control rule can be written as

\section{IF $e(k)$ is A and $\Delta e(k)$ is B THEN $\Delta u(k)$ is $\mathrm{C}$}

where $\mathrm{A}$ and $\mathrm{B}$ are the premise, $\mathrm{C}$ is the conclusion.

The FLC gets error and change of error as inputs. The output is the incremental of the control signal.FLC can be implemented using digital hardware such as digital signal processor or field-programmable gate arrays.

The error signal $e(k)$ and change of error $\Delta e(k)$ are defined as

$$
\begin{gathered}
e(k)=V_{\mathrm{o}}(k)-V_{r e f} \\
\Delta e(k)=e(k)-e(k-1)
\end{gathered}
$$

where $V_{o}(k)$ is the present output voltage, $V_{\text {ref }}$ is the reference output voltage, and $k$ is the sample number. The output of the FLC is an incremental change of the control signal $\Delta u(k)$. Using a digital approximation for integration, the control signal $u(k)$ is obtained as

$$
u(k)=u(k-1)+\Delta u(k)
$$

According to the dynamic behaviour of the converter the knowledge base is generated. Rule base and data base are composed to form the knowledge base. Table 1 are used to determine the decision tables of the rule base, while the membership functions of data base are guided by the PIlike method.

By decreasing the number of decision rules main aim of the dead time and rise time of the system is reduced, to cause the scaling factor of membership function to be large as possible. The triangular membership functions are selected and their scaling factors PI-like methods are tuned.

By restricting the error membership function the stability of the system can be maintained is the next objective. To be precise, mainly the centre of $\mathrm{Z}$ (Zero), and the width of NM (Negative Medium) and PM (Positive Medium) determines the stability of this system. There is no distinct way to attain this objective. Trial and error is the only scheme available to achieve this.

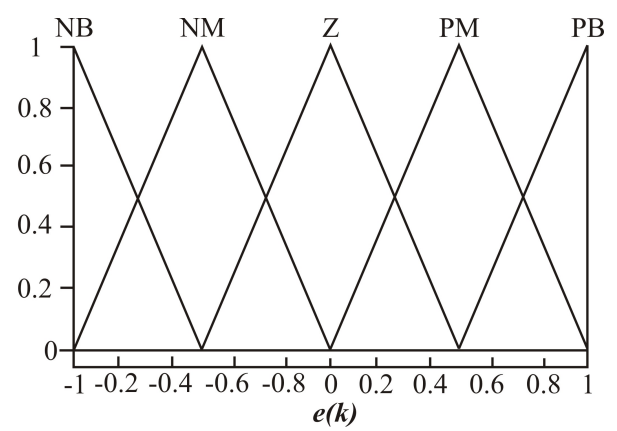

Fig. 2. Membership function of error $e(k)$

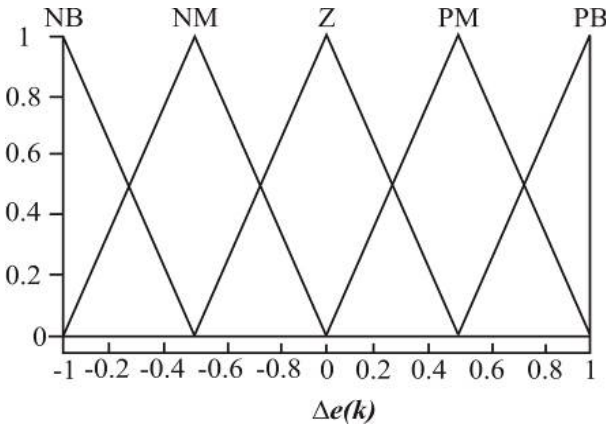

Fig. 3. Membership function of error $\Delta e(k)$

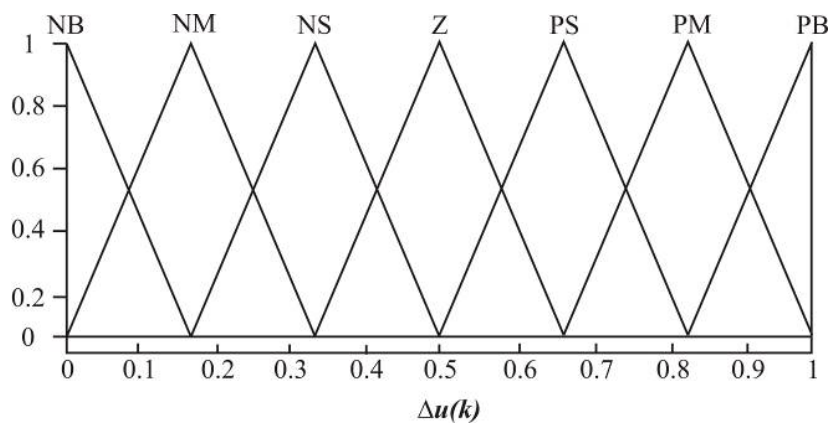

Fig. 4. Membership function of error $\Delta u(k)$

Table 1. Fuzzy rules for computation of $\Delta u(k)$.

\begin{tabular}{c|c|c|c|c|c}
\hline$e(k) \cup e(k)$ & NB & NM & Z & PM & PB \\
\hline NB & NB & NB & NB & NB & NM \\
\hline NM & NB & NM & NS & Z & PS \\
\hline Z & NM & NS & Z & PS & PM \\
\hline PM & NS & Z & PS & PM & PB \\
\hline PB & PM & PB & PB & PB & PB \\
\hline
\end{tabular}

The overall gain is adjusted on line until the system has optimal response is final design step. All MFs of the FLC inputs and the outputare defined on the common normalized domain $[-1,1]$ as shown in Figs. 2-4. The characters NB, NM, NS, Z, PS, PM, PB stand for negative big, negative medium, negative small, zero, positive small, positive medium, and positive big, respectively. Here, triangular MFs are chosen for all fuzzy sets.

The rule base for computing the output $\Delta \mathrm{u}(\mathrm{k})$ is shown in Table 1; this is a frequently used rule base designed with a two-dimensional phase plane. The control rules in Table 1 are built based on the characteristics of the step response. For example, if the output is falling far away from the set point, a large control signal that pulls the output towards the set point is expected, whereas a small control is required when the output is near and approaching the set point.

Fig. 5 and 6 shows the fuzzy rule view and surface view of fuzzy logic controller (FLC) for the proposed converter. These views are constructed by using error $e(k)$, change of error $\Delta e(k)$ and control signal $u(k)$ of fuzzy logic controller. It gives clear idea about how the control signal $u(k)$ 
changes with the error $e(k)$ and change of error $\Delta e(k)$ variations.

\section{APWM Full-bridge DC-DC Boost Converter}

The proposed ZVS full-bridge DC-DC converter with
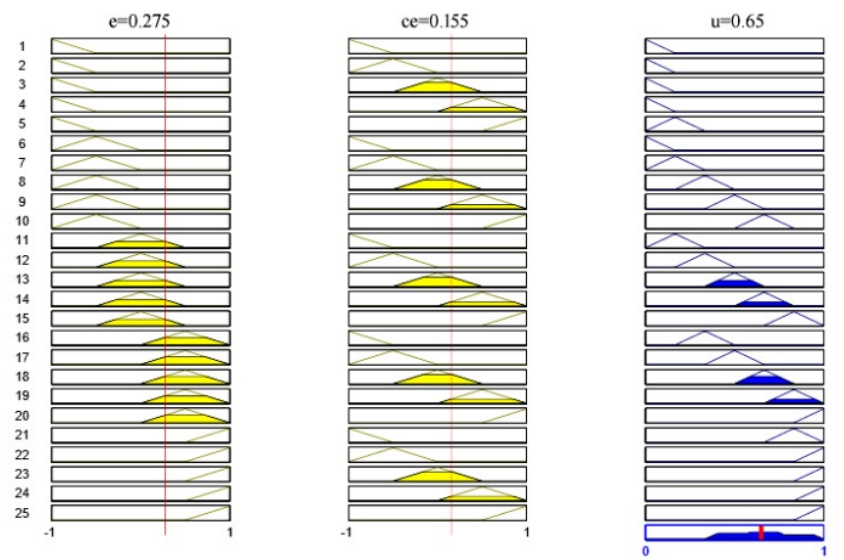

Fig. 5.Fuzzy rule view of T-S FIS

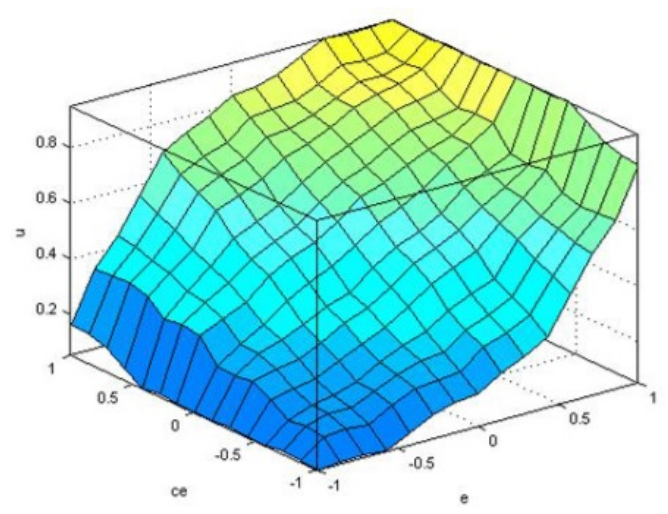

Fig. 6. Surface view of rule base for T-S fuzzy inference system a high voltage gain and a very low ripple input current is shown in Fig. 7. It consists of a new boost converter topology with two boost inductor and an APWM fullbridge converter with a voltage doubler. The boost converter provides a very low ripple input current by utilizing two boost inductors $L_{1}$ and $L_{2}$, input capacitor $C_{i n}$, the auxiliary inductor $L_{d c}$, and the split dc-link capacitors $C_{d c 1}$ and $C_{d c 2}$.

The APWM full-bridge converter provides a high voltage gain, a galvanic isolation, and ZVS operation to all switches $S_{1}$ through $S_{4}$. Moreover, the leakage inductance of the transformer significantly alleviates the reverserecovery problems of the output diodes $D_{o 1}$ and $D_{o 2}$. The diodes $D_{1}$ through $D_{4}$ are the intrinsic body diodes and the capacitors $C_{1}$ through $C_{4}$ are parasitic output capacitances of the full-bridge switches. The transformer is modelled as the magnetizing inductance $L_{m}$, the leakage inductance $L_{k}$, and the ideal transformer which has a turn ratio of $1: n$ (n $\left.=N_{2} / N_{1}\right)$. The switch $S_{1} \& S_{4}$ and the switch $S_{2} \& S_{3}$ are operated asymmetrically and the duty ratio D is based on the switch $S_{2} \& S_{3}$. Proposed converter comprises of four modes of operation and discussed in detail in the following section.

\subsection{Mode 1:}

Fig. 8(a) represents mode 1 operation of proposed converter. Mode 1 starts with the turn-off of $S_{1}$ and $S_{4}$. But, $S_{2}$ and $S_{3}$ are yet to turn on condition and output diode, $D_{o 1}$ is turned on condition. Then, $C_{1}$ and $C_{4}$ are charged and $C_{2}$ and $C_{3}$ are discharged by using the energy stored in the magnetic components. Due to discharge of $C_{2}$ and $C_{3}$, body diodes $D_{2}$ and $D_{3}$ starts to conduct and this interval is very short due to all the parasitic output capacitances $C_{1}$ through $C_{4}$ are very small. This makes voltage across $S_{2}$ and $S_{3}$ is zero. Then, $S_{2}$ and $S_{3}$ are turned on by applying gate pulse. Now, zero voltage switching is achieved for $S_{2}$ and $S_{3}$. Inductors $L_{1}$ get energy from $V_{i n}$ and $L_{2}$ and $L_{d c}$ from $V_{d c 2}$. Fig. 8(a) shows the current flow directions in various components of proposed converter in mode 1 .

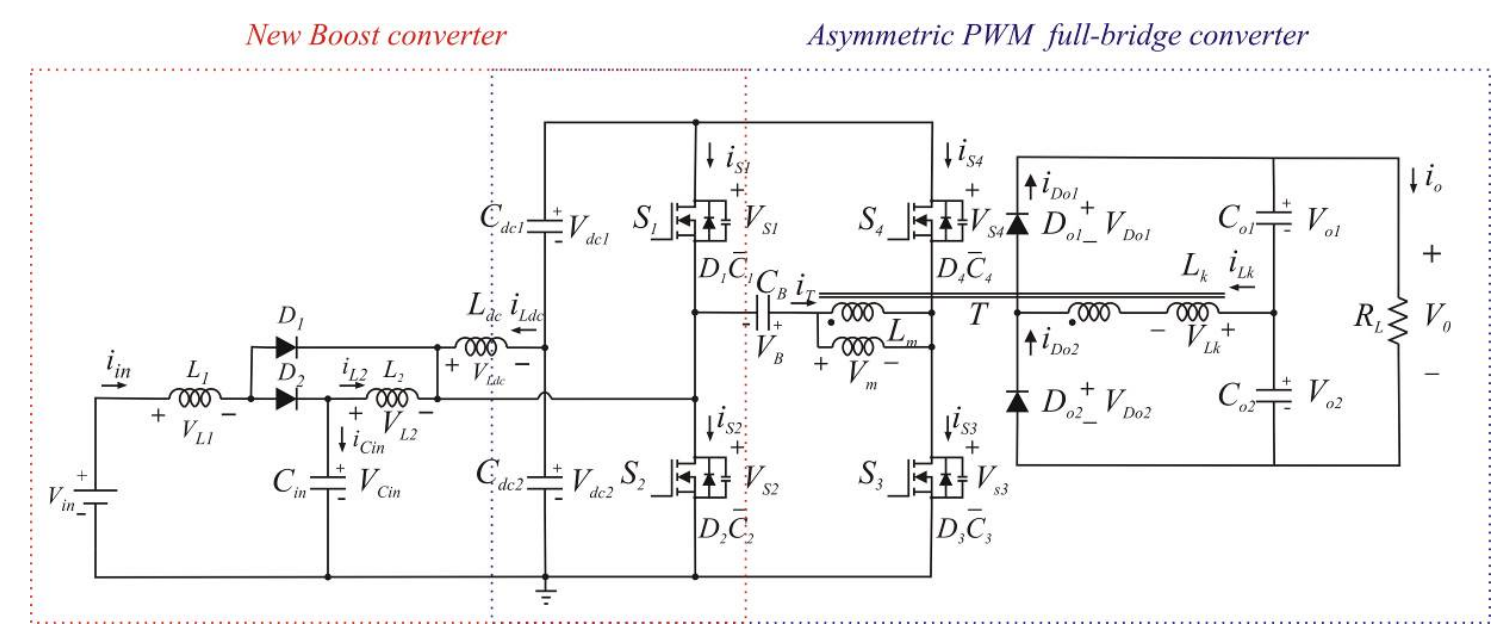

Fig. 7. Circuit diagram of proposed converter 


\subsection{Mode 2:}

Fig. 8(b) represents mode 2 operation of proposed converter. In this mode, output diode $D_{o 1}$ is turned off

automatically due to secondary leakage inductor current, $i_{L k s}$ and this current also alleviate reverse recovery problem of diode, $D_{o 1}$. Then, diode $D_{o 2}$ starts to conduct. Except conduction of diode $D_{o 2}$, mode 2 follows mode 1as shown in Fig. 8(b).

\subsection{Mode 3:}

Fig. 8(c) represents mode 1 operation of proposed converter. Mode 3 starts with the turn-off of $S_{2}$ and $S_{3}$. But, $S_{1}$ and $S_{4}$ are yet to turn on condition and output diode, $D_{o 2}$

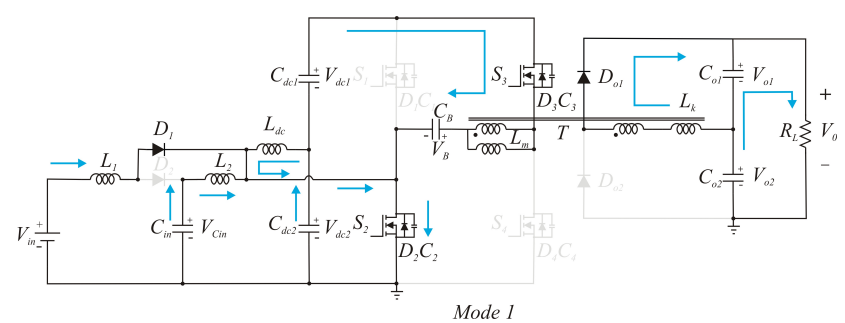

(a)

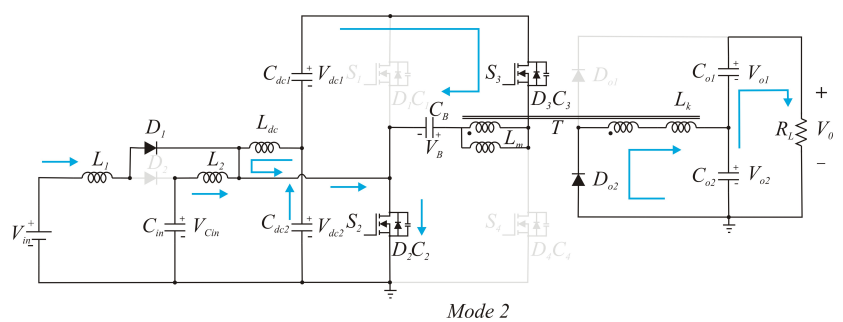

(b)

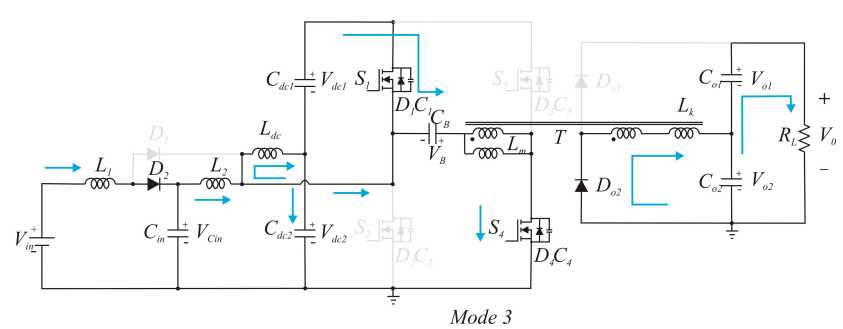

(c)

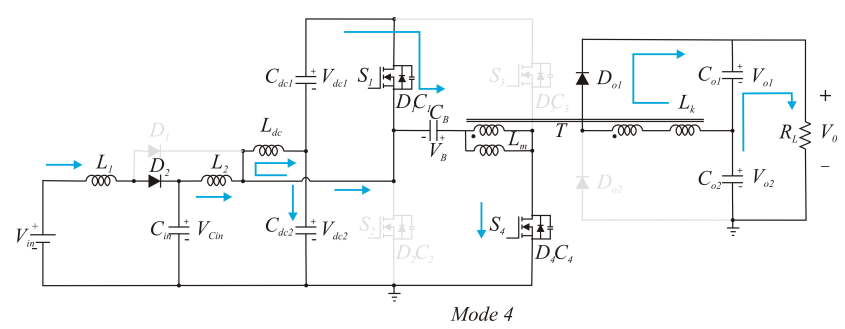

(d)

Fig. 8. Circuit diagram of proposed converter operations of (a) Mode 1 (b) Mode 2 (c) Mode 3 (d) Mode 4 is turned on condition. Then, $C_{2}$ and $C_{3}$ are charged and $C_{1}$ and $C_{4}$ are discharged by using the energy stored in the magnetic components. Due to discharge of $C_{1}$ and $C_{4}$, body diodes $D_{1}$ and $D_{4}$ starts to conduct and this interval is very short due to all the parasitic output capacitances $C_{1}$ through $C_{4}$ are very small. This makes voltage across $S_{1}$ and $S_{4}$ is zero. Then, $S_{1}$ and $S_{4}$ are turned on by applying gate pulse. Now, zero voltage switching is achieved for $S_{1}$ and $S_{4}$. Then, voltage source, $V_{i n}$, inductors $L_{1}, L_{2}$ and $L_{d c}$ through $C_{d c 1}$ delivers its energy to transformer primary winding. Fig. 8(c) shows current flow directions in various components of proposed converter in mode 3 .

\subsection{Mode 4:}

Fig. 8(d) represents mode 4 operation of proposed converter. In this mode, output diode $D_{o 2}$ is turned off automatically due to secondary leakage inductor current, $i_{L k s}$ and this current also alleviate reverse recovery problem of diode, $D_{o 2}$. Then, diode $D_{o 1}$ starts to conduct. Except conduction of diode $D_{o 1}$, mode 4 follows mode 3 as shown in Fig. 8(d).

Major drawbacks of conventional full bridge converter are high switching loss due to hard switching and exorbitant voltage stresses of switches. To reduce the voltage stresses across the switches, additional snubber circuits are required. Since, passive snubber circuits increases power loss and reduce the system efficiency, active snubber circuits are preferred for suppressing voltage stresses. However, complexity and cost of the system increases due to inclusion of extra switches. These shortcomings are easily overcome by the proposed converter without sacrificing system efficiency and performance. Moreover, in Full bridge converter, voltage doubler circuit is connected in secondary side of transformer which makes current sharing possible. Therefore, current stress and temperature will be within the limits only for proposed converter. Also, the comparison of vital parameters presented in Table 2 is in favour of proposed converter only.

\section{Simulation Results}

The proposed converter is designed in PSIM as shown in Fig. 9 and proposed converter control scheme is

Table 2. Circuit parameters of the proposed converter

\begin{tabular}{c|c}
\hline Parameter & Value \\
\hline Inductance $\mathrm{L}_{1}$ and $\mathrm{L}_{2}$ & $500 \mu \mathrm{H}$ \\
\hline Inductance $\mathrm{L}_{\mathrm{dc}}$ & $33 \mu \mathrm{H}$ \\
\hline Input capacitance $\mathrm{C}_{\mathrm{in}}$ & $470 \mu \mathrm{F}$ \\
\hline Output capacitance $\mathrm{C}_{\mathrm{o}}$ & $470 \mu \mathrm{F}$ \\
\hline DC-blocking capacitor $\mathrm{C}_{\mathrm{B}}$ & $6.6 \mu \mathrm{F}$ \\
\hline DC link capacitance $\mathrm{C}_{\mathrm{dc}}$ and $\mathrm{C}_{\mathrm{dc} 2}$ & $470 \mu \mathrm{F}$ \\
\hline Transformer turns ratio & $1: 3$ \\
\hline Primary magnetizing inductance $\mathrm{L}_{\mathrm{m}}$ & $220 \mu \mathrm{H}$ \\
\hline Secondary leakage inductance $\mathrm{L}_{\mathrm{ks}}$ & $20 \mu \mathrm{H}$ \\
\hline
\end{tabular}




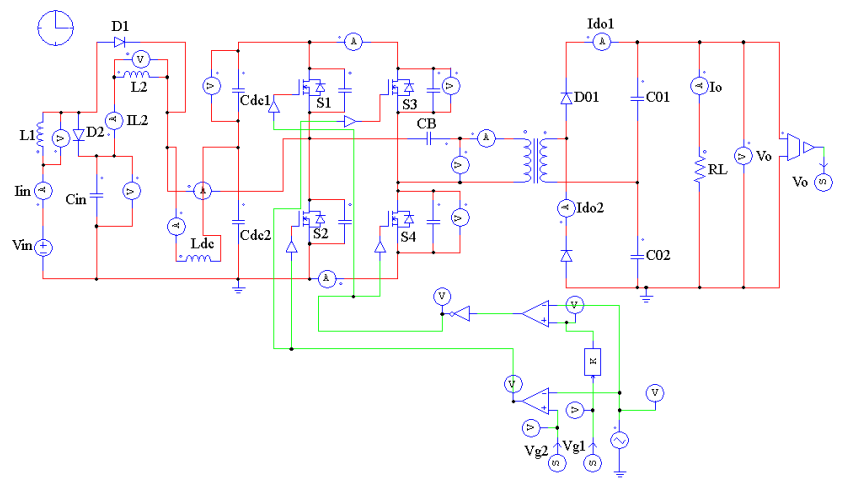

Fig. 9. PSIM simulation circuit of proposed converter

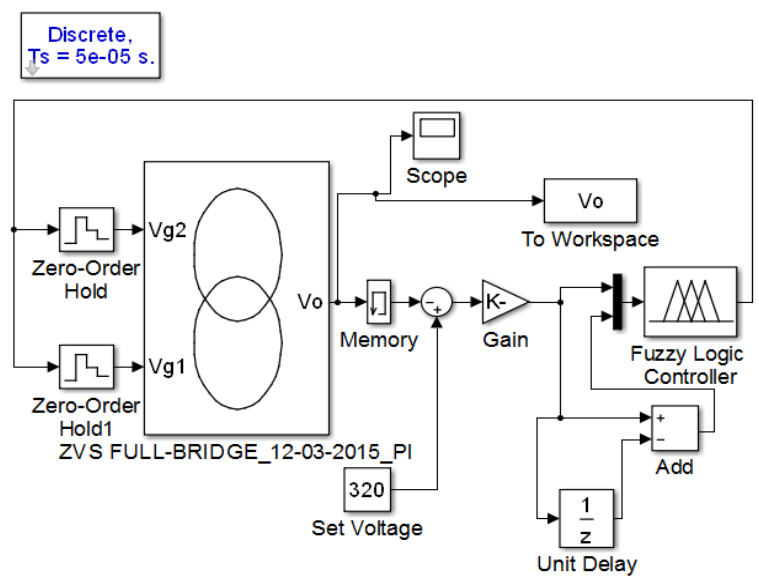

Fig. 10. Matlab/Simulink controller model of proposed converter

constructed in Matlab $₫ / \operatorname{Simulink} \circledast$ as shown in Fig. 10. Two different simulation simulation platforms, i.e., PSIM ${ }^{\circledR}$ and Matlab ${ }^{\circledR} / \operatorname{Simulink}{ }^{\circledR}$ is integrated to study the performance of proposed converter and control scheme for line input variations and set value changes. For integrating these two software platforms PSIM ${ }^{\circledR}$ SimCoupler tool is used. It integrates these two platforms efficiently. Table 2 shows the circuit parameters of the proposed converter.

Fig. 11 and 12 shows the response curve of the proposed converter with proportional integral (PI) controller and fuzzy logic controller (FLC) for input voltage step variation from $24 \mathrm{~V}$ to $32 \mathrm{~V}$ and from $32 \mathrm{~V}$ to $24 \mathrm{~V}$. Both controllers provide very small negligible steady state error. PI controller has taken long time to reach its steady value and produced undershoot during dynamic conditions. By investigating proportional integral and fuzzy logic controller (FLC) responses for the proposed converter, fuzzy logic controller (FLC) gives very fast response for input changed or line regulation with very low steady state error which can be ignored.

Fig. 13 and 14 shows the response curve of the proposed converter with proportional integral (PI) controller and fuzzy logic controller (FLC) for set or reference voltage step variation from $320 \mathrm{~V}$ to $270 \mathrm{~V}$ and from $270 \mathrm{~V}$ to $320 \mathrm{~V}$. PI controller gives slow response to reach its expected

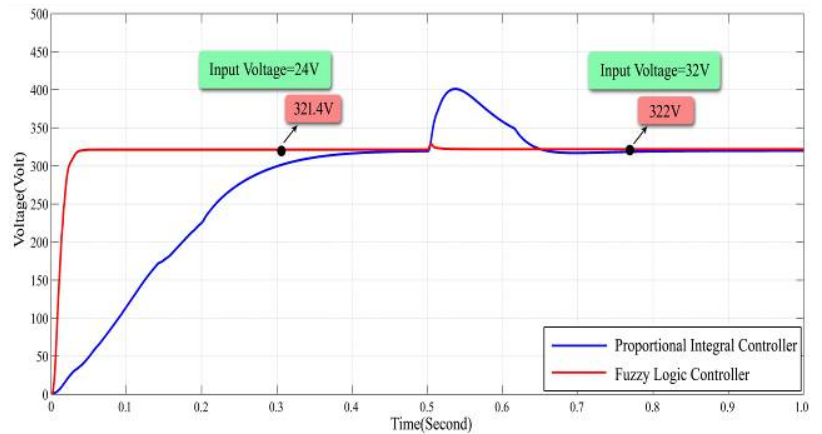

Fig. 11. Response of proposed converter for input voltage variation from $24 \mathrm{~V}$ to $32 \mathrm{~V}$

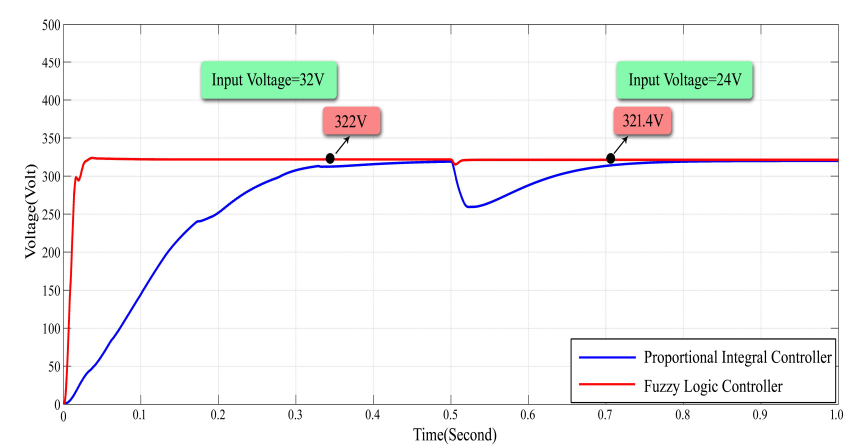

Fig. 12. Response of proposed converter for input voltage variation from $32 \mathrm{~V}$ to $24 \mathrm{~V}$

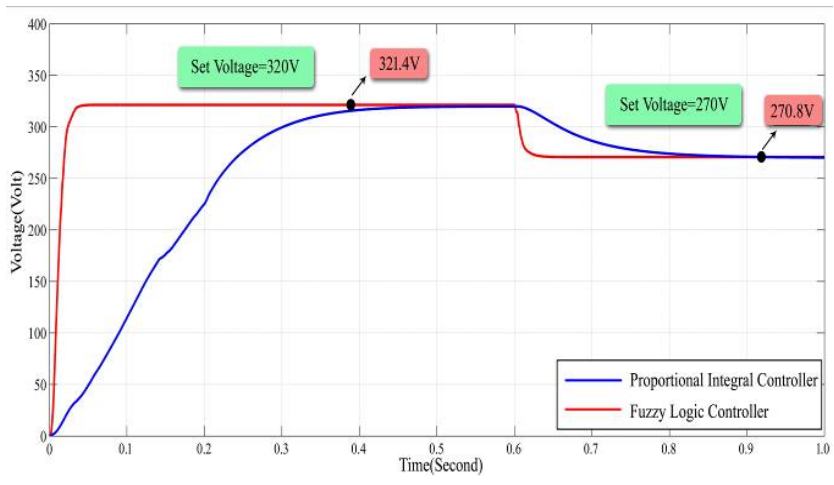

Fig. 13. Response of proposed converter for input voltage $24 \mathrm{~V}$ with set voltage variation from $320 \mathrm{~V}$ to $270 \mathrm{~V}$

Table 3. Performance parameters from simulation output

\begin{tabular}{c|c|c|c}
\hline & $\begin{array}{c}\text { Rise time } \\
\text { (second) }\end{array}$ & $\begin{array}{c}\text { Settling time } \\
\text { (second) }\end{array}$ & $\begin{array}{c}\text { Steady-state } \\
\text { error (volt) }\end{array}$ \\
\hline PI controller & 0.1794 & 0.3254 & $-2 \mathrm{~V}$ \\
\hline Fuzzy logic controller & 0.0224 & 0.0184 & $0.6 \mathrm{~V}$ \\
\hline
\end{tabular}

values.

The proposed converter with fuzzy logic controller (FLC) gives fast response to reach its set values change. But it gives very small percentage of steady state error. By investigating the proposed converter response with proportional integral controller, fuzzy logic controller (FLC) 
gives very fast response for set or reference value changes with very low steady state error which is negligible. Performance parameters observed from simulation output are compared between proposed fuzzy logic controller (FLC) and proportional integral controller (PI) is given in Table 3.

\section{Experimental results}

The experimental setup of proposed fuzzy logic controlled converter is shown in Fig. 15. Table 4 shows various components and its values used for experimental setup of the proposed converter for real-time validation of simulated results. A 120 watts load is connected and the fuzzy logic controller (FLC) is implemented using PIC Microcontroller. Hardware response is achieved and it is also in line with simulated outputs with acceptable practical deviations.

Fig. 16(a) and (b) gives the real-time output voltage response for the input voltage variations form $24 \mathrm{~V}$ to $32 \mathrm{~V}$ and from $32 \mathrm{~V}$ to $24 \mathrm{~V}$. Fuzzy controller makes the converter

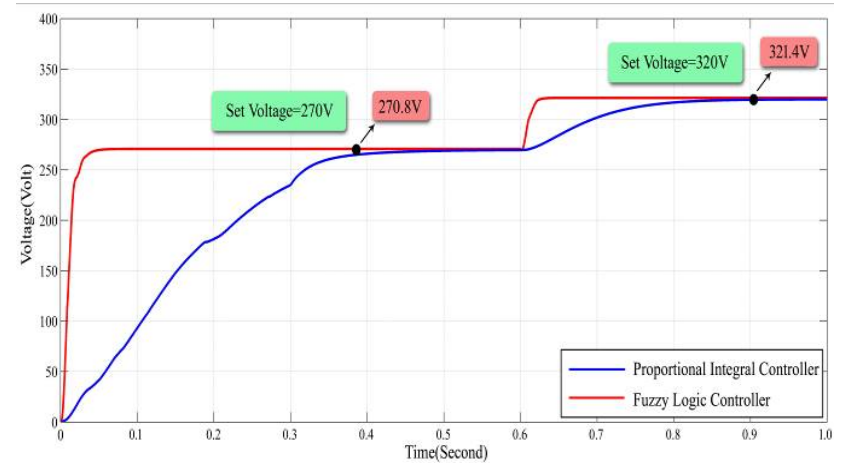

Fig. 14. Response of proposed converter for set voltage variation from $270 \mathrm{~V}$ to $320 \mathrm{~V}$ to reach its rated voltage of around $320 \mathrm{~V}$ with the negligible settling time with acceptable overshoot and undershoot for line regulation or input variation.

With constant load by changing set value or reference voltage of fuzzy logic controlled converter from $270 \mathrm{~V}$ to $320 \mathrm{~V}$ and $320 \mathrm{~V}$ to $270 \mathrm{~V}$, converter gives fast response with acceptable overshoot and undershoot to reach its expected output voltage is shown in Fig. 17(a) and b. From the experimental results, fuzzy logic controller makes this converter to give fast response for line regulation or input voltage variations and set value or reference voltage variations with acceptable deviation from simulation results. From experimental response for line regulation, converter gives acceptable practical overshoot and undershoots.

For set value or reference value variations, converter gives real-time overshoot and undershoots. After investigation of experimental output responses, performance parameters of proposed converter are derived and are given in Table 5. The occurrence of overshoot and undershoot in

Table 4. Parameter values for the experimental set up

\begin{tabular}{c|c}
\hline Parameter & Value \\
\hline Input voltage, $V_{\text {in }}$ & $24-34 \mathrm{~V}$ \\
\hline Switching frequency, $f_{S W}$ & $100 \mathrm{KHz}$ \\
\hline Output voltage, $V_{o}$ & $320 \mathrm{~V}$ \\
\hline MOSFET $\left(S_{1}, S_{2}, S_{3} \& S_{4}\right)$ & IXFH22N60P3 \\
\hline Power diode $\left(D_{1} \& D_{2}\right)$ & RURG8060 \\
\hline Output Diode (Ultra-fast recovery diode) & RURG3060 \\
\hline Primary magnetizing inductance $\mathrm{L}_{\mathrm{m}}$ & $222.4 \mu \mathrm{H}$ \\
\hline Secondary leakage inductance $\mathrm{L}_{\mathrm{ks}}$ & $21.3 \mu \mathrm{H}$ \\
\hline
\end{tabular}

Table 5. Performance parameters from experimental output

\begin{tabular}{c|c|c|c}
\hline & $\begin{array}{c}\text { Rise time } \\
\text { (second) }\end{array}$ & $\begin{array}{c}\text { Settling time } \\
\text { (second) }\end{array}$ & $\begin{array}{c}\text { teady-state error } \\
\text { (volt) }\end{array}$ \\
\hline FLC (line regulation) & 0.0092 & 0.068 & $-1 \mathrm{~V}$ \\
\hline FLC (Set value change) & 0.01 & 0.053 & $2 \mathrm{~V}$ \\
\hline
\end{tabular}

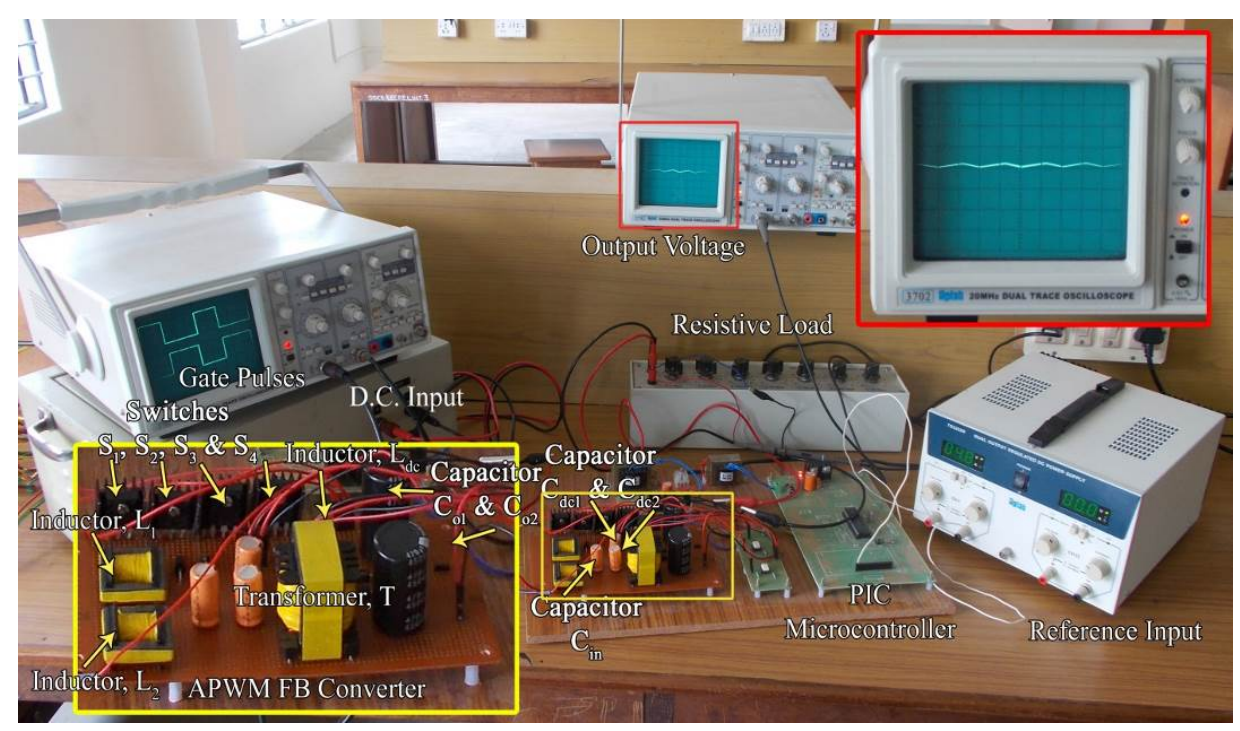

Fig. 15. Experimental hardware setup of proposed system 


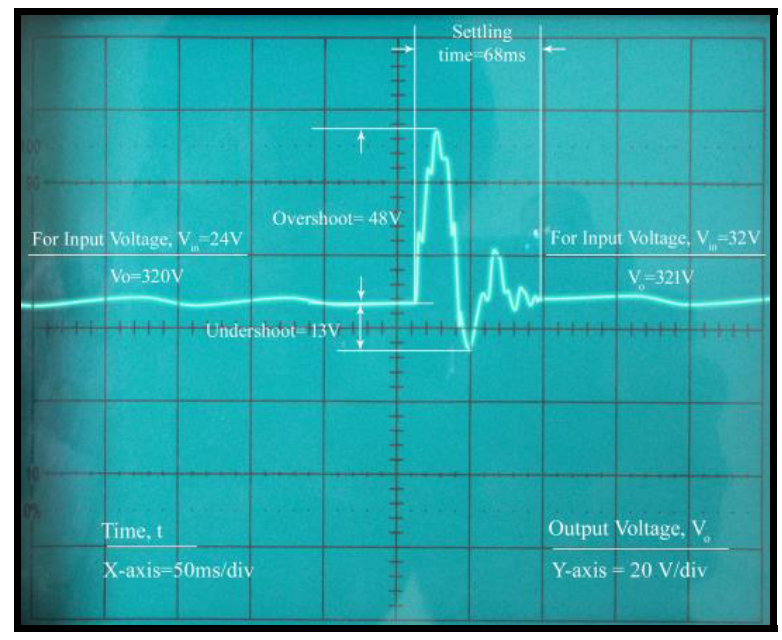

(a)

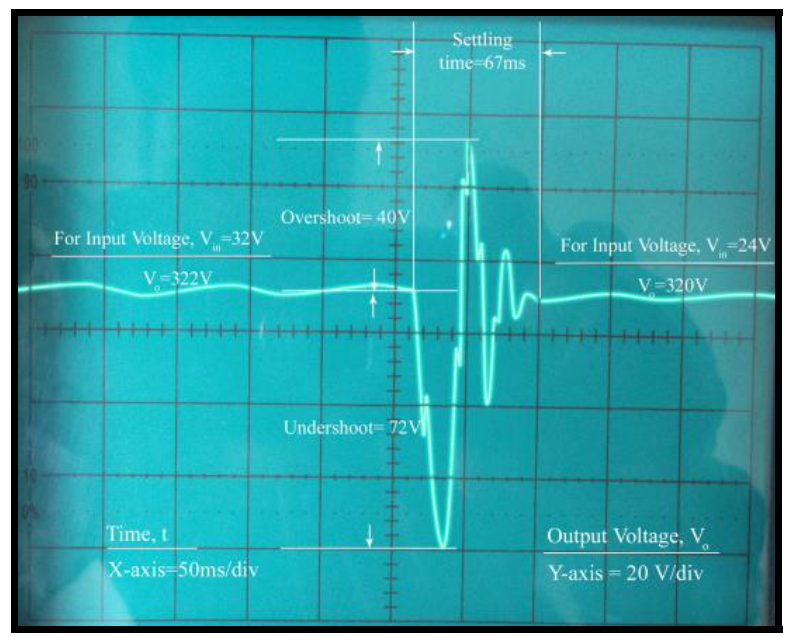

(b)

Fig. 16. Line regulation of proposed converter with (a) step changes in input from $24 \mathrm{~V}$ to $32 \mathrm{~V}$, (b) step changes in input from $32 \mathrm{~V}$ to $24 \mathrm{~V}$

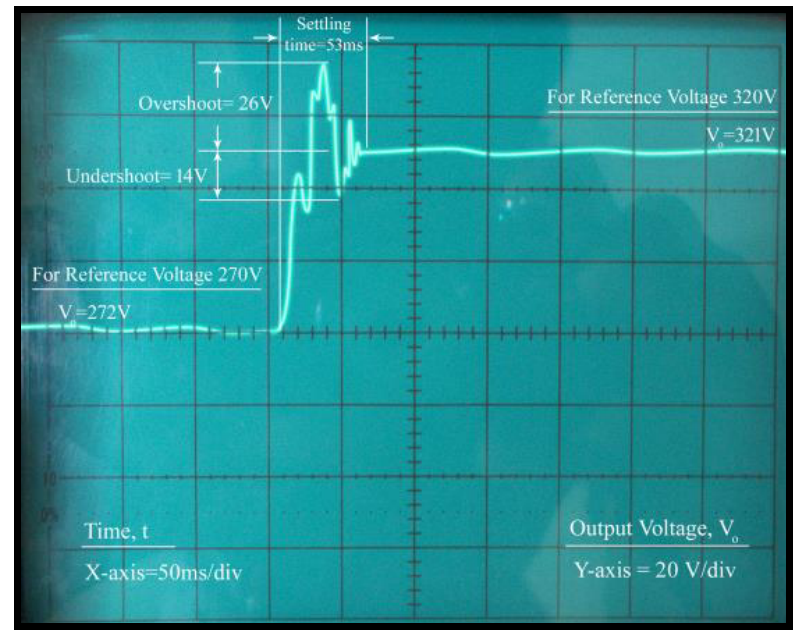

(a)

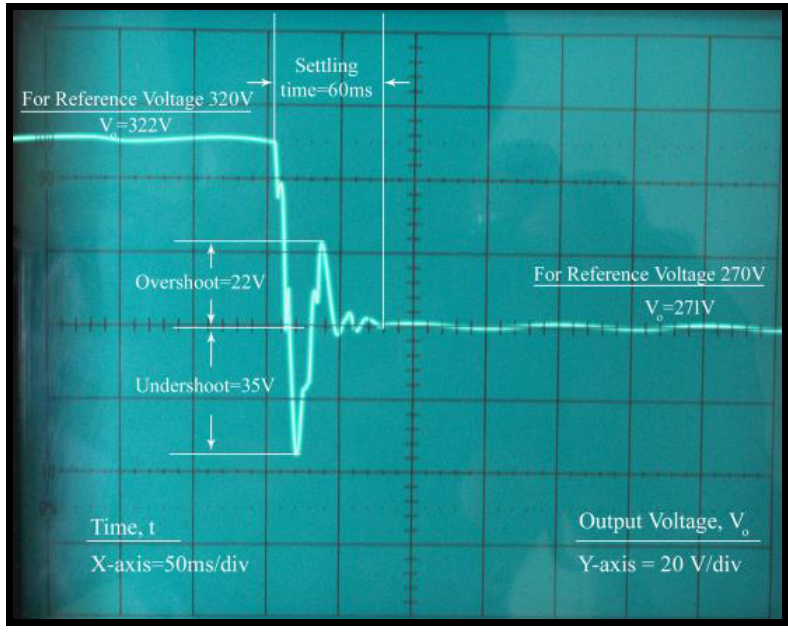

(b)

Fig. 17. Output voltage of the proposed converter with, (a) step changes in reference input from $320 \mathrm{~V}$ to $270 \mathrm{~V}$ and (b) step changes in reference input from $270 \mathrm{~V}$ to $320 \mathrm{~V}$

experimental waveforms is mainly due to number of energy storing passive components present in the proposed converter boost stage side and also in the transformer secondary side. It is well within the customer requirement value of less than 20\%. Even though overshoot and undershoot appears high in the experimental output, it settles fast to the set point. So, it seldom creates major problem. Moreover, modern power semiconductor devices have capability to withstand short time voltage/current transients during dynamic conditions.

\section{Conclusions}

The analysis, design, simulation and hardware results of a fuzzy controller for ZVS asymmetrical full-bridge DCDC converter with a high voltage gain and a low ripple input current for constant load and high power applications have been presented. The fuzzy logic controller aids this converter to provide dynamic and fast response under varying input voltage and variable set voltage conditions. The controller displays very remarkable features such as simplicity (no linearization is required) and fast responses. The proposed converter with controller improves the efficiency. Various test cases have shown that the fuzzy logic controller structure for this converter is having the capability of reducing the effect of different disturbances such as set or reference voltage changes and input voltage variations commonly found in industry. The fuzzy logic controller is robust and can easily be implemented on a 
microcomputer. Experimental results on a $120 \mathrm{~W}$ load prototype have been provided to validate the proposed concept. Based on the encouraging simulation as well as hardware results, it can be ascertained that, the converter with the proposed converter with controller can be very well implemented as interface between renewable energy source output and loads.

\section{References}

[1] M.H. Taghvaee, M.A.M. Radzi, S.M. Moosavain, Hashim Hizam and M. Hamiruce Marhaban, "A current and future study on non-isolated DC-DC converters for photovoltaic applications," Renewable and Sustainable Energy Reviews, vol. 17, pp. 216227, 2013.

[2] Kia Filsoof, Abdel rahman A.Hagar, Peter W. Lehn, "A transformerless modular step-up dc-dc converter for high power applications," IET Power Electronics, vol. 7, no. 8, pp. 2190-2199, 2014.

[3] Amari Mansour, Bacha Faouzi, Ghouili Jamel, Elgharbi Ismahen, "Design and analysis of a high frequency DC-DC converters for fuel cell and supercapacitor used in electric vehicles, "Journal of Hydrogen Energy, vol. 39, pp. 1580-1592, 2014.

[4] Tohid Nouri, Ebrahim Babaei and Seyed Hossein Hosseini, "A generalized ultra step-up DC-DC converter for high voltage application with design considerations, "Electric Power Systems Research, vol. 105, pp. 71-84, December 2013.

[5] Ahmad J. Sabzali, Esam H. Ismail and Hussain M. Behbehani, " High voltage step-up integrated double Boost-Sepic DC-DC converter for fuel cell and photovoltaic applications," Renewable Energy, vol. 82, pp. 44-53, October 2015.

[6] Keshav Patidar and Amod C. Umarikar, "High stepup converters based on quadratic boost converter for micro-inverter," Electric Power System Research, vol. 119, pp. 168-77, February 2015.

[7] Hassan Fathabadi, "Novel high efficiency DC/DC boost converter for using in photovoltaic systems," Solar Energy, vol. 125, pp. 22-31, February 2016.

[8] Akshay K. Rathore, "Interleaved soft-switched active-clamped L-L type current fed half-bridge DCDC converter for fuel cell applications," Journal of Hydrogen Energy, vol. 34, pp. 9802-9815, 2009.

[9] Heeji Kim, Jongrak Kim, Hosung Kim, Kyungjun Lee, Jonghyun Kim, Dongwook Yoo and Dongsul Shin, "A high efficiency photovoltaic module integrated converter with the asymmetrical halfbridge flyback converter," Solar Energy, vol. 84, pp. 1376-1381, 2010.

[10] M.A. Farahat, H.M.B. Metwally and Ahmed AbdElfatah Mohammed, "Optimal choice and design of different topologies of DC-DC converter used in PV systems at different climatic conditions in Egypt," Renewable Energy, vol. 43, pp. 393-402, 2012.

[11] X.Kong and A.M.Khambadkone, "Analysis and implementation of a high efficiency, interleaved current fed full-bridge converter for fuel cell system," IEEE Trans. Power Electron., vol. 22, pp. 543-550, March 2007.

[12] Doo-Yong Jung, Young-Hyok Ji, Sang-Hoon Park, Yong-Chae Jung and Chung-Yuen Won, "Interleaved Soft-Switching Boost converter for Photovoltaic Power Generation System," IEEE Trans. Power Electron., vol. 26, no. 4, April 2011.

[13] Dong-Myoung Joo, Dong-Hee Kim and Byoung-Kuk Lee, "DCM frequency control algorithm for multiphase DC-DC Boost converters for Input current ripple reduction," J Electr Eng Technol., vol. 10, no. 6, pp. 2307-2314, 2015.

[14] A. Abdullah, M.M. Al-Hindawi, Y. Al-Turki, K. Mandal, Damian Giaouris, Soumitro Banerjee, Spyros Voutetakis and Simira Papadopoulou, "Stability of a boost converter fed from photovoltaic source," Solar Energy, vol. 98, pp. 458-471, 2013.

[15] P. Imbertson and N. Mohan, "Asymmetrical duty cycle permits zero switching loss in PWM circuits with no conduction loss penalty," IEEE Trans. Ind. Appl. vol. 29, pp. 121-125, Jna./Feb. 1993.

[16] Sang-Wha Seo, Han Ho Choi and Young Kim, "Takagi-Sugeno Fuzzy model based approach to robust control of boost DC-DC converters," J Electr. Eng. Technol., vol. 10, no. 3, pp. 925-934, 2015.

[17] C.Sreekumar and Vivek Agarwal, "A hybrid control algorithm for voltage regulation in DC-DC boost converter," IEEE Trans. Industrial Electron., vol. 55, no. 6, June 2008.

[18] Arnab Ghosh, Subrata Banerjee, Mrinal Kanti Sarkar and Priyanka Dutta, "Design and implementation of type-II and type-III controller for DC-DC switchedmode boost converter by using K-factor approach and optimisation techniques," IET Power Electronics, vol. 9, no. 5, pp. 938-950, 2016.

[19] Sakda Somkun, Chatchai Sirisamphanwong and Surkuedee Sukchai, "A DSP-based interleaved boost DC-DC converter for fuel cell applications," Journal of Hydrogen Energy, vol. 40, no. 19, pp. 6391-6404, 25 May 2015.

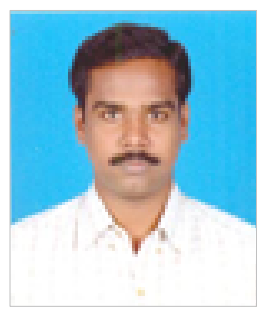

Marikkannan.A He obtained his B.E. degree in Electrical and Electronics Engineering during 2003 from Madurai Kamaraj University, Madurai. $\mathrm{He}$ obtained his M.E. degree in Power Electronics and Drives during 2010 from Anna University of Technology, Tirunelveli. He is pursuing his research 
in Anna University, Chennai. His research interests include high-power dc-dc converter for renewable energy, hybrid electric vehicle and Electrical Machines. Presently, he is working as Assistant Professor in the Electrical and Electronics Engineering department of Sree Sowdambika College of Engineering, Aruppukottai, Tamilnadu, India.

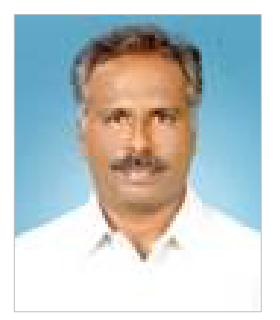

Manikandan.B.V. He obtained his B.E. degree in Electrical and Electronics Engineering during 1990 and M.E. degree in Power Systems Engineering during 1992 from Madurai Kamaraj University. He obtained his Ph.D. degree from Anna University, Chennai in the year 2010. His special fields of interest include power system restructuring issues, FACTS controllers, Special machines and Drives \& Controls. Presently, he is working as Professor in the Electrical and Electronics Engineering department of Mepco Schlenk Engineering College, Sivakasi, Tamilnadu, India. 